\title{
Diagnostic accuracy of the bronchodilator response in children
}

\section{Citation}

Tse, Sze Man, Diane R. Gold, Joanne E. Sordillo, Elaine B. Hoffman, Matthew W. Gillman, Sheryl L. Rifas-Shiman, Anne L. Fuhlbrigge, Kelan G. Tantisira, Scott T. Weiss, and Augusto A. Litonjua. 2013. Diagnostic accuracy of the bronchodilator response in children. Journal of Allergy and Clinical Immunology 132, no. 3: 554-559.e5. doi:10.1016/j.jaci.2013.03.031.

\section{Published Version}

doi:10.1016/j.jaci.2013.03.031

\section{Permanent link}

http://nrs.harvard.edu/urn-3:HUL.InstRepos:27005840

\section{Terms of Use}

This article was downloaded from Harvard University's DASH repository, and is made available under the terms and conditions applicable to Open Access Policy Articles, as set forth at http:// nrs.harvard.edu/urn-3:HUL.InstRepos:dash.current.terms-of-use\#OAP

\section{Share Your Story}

The Harvard community has made this article openly available.

Please share how this access benefits you. Submit a story.

\section{Accessibility}




\title{
Diagnostic accuracy of the bronchodilator response in children
}

\author{
Sze Man Tse, MDCM, MPH ${ }^{a}, b$, Diane R. Gold, MD, MPH ${ }^{a}$, Joanne E. Sordillo, ScD ${ }^{a}$, Elaine B. \\ Hoffman, PhD $^{\mathrm{c}}$, Matthew W. Gillman, MD, $\mathbf{S M}^{\mathrm{d}}$, Sheryl L. Rifas-Shiman, MPH $^{\mathrm{d}}$, Anne L. \\ Fuhlbrigge, MD, MS ${ }^{a}$, Kelan G. Tantisira, MD, MPH ${ }^{\mathrm{a}}$, Scott T. Weiss, MD, MS ${ }^{\mathrm{a}}$, and Augusto \\ A. Litonjua, MD, MPH ${ }^{a}$ \\ athe Channing Division of Network Medicine, Department of Medicine, Brigham and Women's \\ Hospital and Harvard Medical School, Boston, Mass \\ bMassachusetts General Hospital, Department of Pediatrics, Division of Pediatric Pulmonary \\ Medicine, Boston, Mass \\ cHarvard School of Public Health, Department of Biostatistics, Boston, Mass \\ ${ }^{d}$ the Obesity Prevention Program, Department of Population Medicine, Harvard Medical School \\ and Harvard Pilgrim Health Care, Boston, Mass
}

\section{Abstract}

Background-The bronchodilator response (BDR) reflects the reversibility of airflow obstruction and is recommended as an adjunctive test to diagnose asthma. The validity of the commonly used definition of BDR, a $12 \%$ or greater change in $\mathrm{FEV}_{1}$ from baseline, has been questioned in childhood.

Objectives-We sought to examine the diagnostic accuracy of the BDR test by using 3 large pediatric cohorts.

Methods-Cases include 1041 children with mild-to-moderate asthma from the Childhood Asthma Management Program.

Control subjects (nonasthmatic and nonwheezing) were chosen from Project Viva and Home Allergens, 2 population-based pediatric cohorts. Receiver operating characteristic curves were constructed, and areas under the curve were calculated for different BDR cutoffs.

Results-A total of 1041 cases (59.7\% male; mean age, $8.9 \pm 2.1$ years) and 250 control subjects (46.8\% male; mean age, $8.7 \pm 1.7$ years) were analyzed, with mean BDRs of $10.7 \% \pm 10.2 \%$ and $2.7 \% \pm 8.4 \%$, respectively. The BDR test differentiated asthmatic patients from nonasthmatic patients with a moderate accuracy (area under the curve, 73.3\%).

Despite good specificity, a cutoff of $12 \%$ was associated with poor sensitivity (35.6\%). A cutoff of less than $8 \%$ performed significantly better than a cutoff of $12 \%(P=.03,8 \%$ vs $12 \%)$.

Conclusions-Our findings highlight the poor sensitivity associated with the commonly used $12 \%$ cutoff for BDR. Although our data show that a threshold of less than $8 \%$ performs better than $12 \%$, given the variability of this test in children, we conclude that it might be not be appropriate to choose a specific BDR cutoff as a criterion for the diagnosis of asthma.

\section{Keywords}

Asthma; bronchodilator response; diagnosis

In asthmatic patients the response to bronchodilators reflects the reversibility of airway airflow obstruction. High bronchodilator response (BDR) in asthmatic patients has been 
(Coordinator); Melinda Solomon, MD; Padmaja Subbarao, MD. Ian MacLusky, MD, FRCP (Director 1999-2007); Joe Reisman, MD, FRCP(C), MBA (Director, 1996-1999); Henry Levison, MD, FRCP(C) (Director, 1992-1996); Anita Hall, RN (Coordinator, 1993-2007). Yola Benedet (1994-1999); Susan Carpenter, RN (1998-2001); Jennifer Chay (2004); Michelle Collinson, RN (1994-1998); Jane Finlayson-Kulchin, RN (1994-1998); Kenneth Gore, MA (1993-1999); Nina Hipolito, RN (2003-2004); Noreen

Tse Pbłhnes, RRT (1998-1999); Erica Hoorntje, RN (2002-2003); Sharon Klassen, MA (1999-2000); Joseé Quenneville, MSc Page 2 (1993-1995); Renée Sananes, PhD (1993-2004); Christine Wasson, PhD (1999); Margaret Wilson, RN (2001-2002).

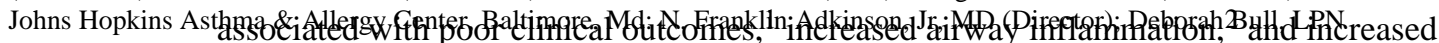
(Coordinator); Stephanie Philips, RN. Peyton Eggleston, MD (Co-Director, 1991-2004); Karen Huss, DNSc (Co-Investigator, 1991-2004); Leslie Plotnick, MD (Co-Investigator, 1991-1999); Margaret Pulsifer, PhD (Co-Investigator, 1993-2004); Cynthia Rand, $\mathrm{PhD}$ (Co-Investigator, 1991-2004). Elizabeth Aylward, PhD (1991-2004), Nancy Bollers, RN (Coordinator, 1993-2004); Kathy Pessaro (2004-2007); Barbara Wheeler, RN, BSN (Coordinator, 1991-1999).

National Jewish Health, Denver, Colo: Stanley Szefler, MD (Director); Ronina Covar, MD (Medical Director); Harold S. Nelson, MD (Co-Director 1991-2000, Co-Investigator 2000-present); Bruce Bender, PhD (Co-Investigator); Andrew Liu, MD (CoInvestigator); D. Sundström (Coordinator); Melanie Phillips; Michael P. White; Melanie Gleason, PA-C. Kristin Brelsford (1997-1999); Jessyca Bridges (1995-1997); Jody Ciacco (1993-1996); Michael Eltz (1994-1995); Jeryl Feeley, MA (Coordinator, 1992-1995); Michael Flynn (1995-1996); Tara Junk-Blanchard (1997-2000); Joseph Hassell (1992-1998); Marcia Hefner (1992-1994); Caroline Hendrickson, RN (1995-1998; Coordinator, 1995-1997); Daniel Hettleman, MA (1995-1996); Charles G. Irvin, PhD (1992-1998); Alan Kamada, PharmD (1994-1997); Marzena Krawiec, MD (2008-2010); Gary Larsen, MD (Co-Investigator, 2000-2010); Sai Nimmagadda, MD (1993-1996); Kendra Sandoval (1995-1997); Jessica Sheridan (1994-1995); Joseph Spahn, MD (Co-Investigator 1993-2010); Gayle Spears, PA-C (2003-2007); Trella Washington (1993-1997); Eric Willcutt, MA (1996-1997). We also thank the pediatric allergy/immunology and pulmonary fellows for their participation: Ivan Cardona, MD; Kirstin Carel, MD; Jayna Doshi, MD; Rich Hendershot, MD; Jeffrey Jacobs, MD; Neal Jain, MD; June-ku Brian Kang, MD; Tracy Kruzick, MD; Harvey Leo, MD; Beth Macomber, MD; Jonathan Malka, MD; Chris Mjaanes, MD; John Prpich, MD; Lora Stewart, MD; Ben Song, MD; Grace Tamesis, MD.

University of California, San Diego, and Kaiser Permanente Southern California Region, San Diego, Calif: Robert S. Zeiger, MD, $\mathrm{PhD}$ (Director); Noah Friedman, MD (Co-Investigator); Michael H. Mellon, MD (Co-Investigator); Michael Schatz, MD (CoInvestigator); Terrie Long, RN (Coordinator). Travis Macaraeg. Sandra Christensen, MD (2004-2007); James G. Easton, MD (CoDirector, 1993-1994); M. Feinberg (1997-1998); Linda L. Galbreath (1991-2002); Jennifer Gulczynski (1998-1999); Kathleen Harden, RN (Coordinator, 1993-2010); Ellen Hansen (1995-1997); Al Jalowayski, PhD (Co-Investigator, 1991-2005); Elaine Jenson (2004-2007); Alan Lincoln, PhD (Co-Investigator, 1991-2003); Jennie Kaufman (1994); Shirley King, MSW (1992-1999); Brian Lopez (1997-1998); Michaela Magiari-Ene, MA (1994-1998); Kathleen Mostafa, RN (1994-1995); Avraham Moscona (1994-1996); Catherine A. Nelle, RN (1991-2005); Jennifer Powers (2001-2003); Elsa Rodriguez (2003-2007); Eva Rodriguez, RRT (1994-2008); Karen Sandoval (1995-1996); Nevin W. Wilson, MD (Co-Director, 1991-1993).

University of New Mexico, Albuquerque, NM: Hengameh H. Raissy, PharmD (Director); Aaron Jacobs (Co-Investigator); H. William Kelly, PharmD (Director, 1998-2011); Mary Spicher, RN (Coordinator). Christina Batson; Michelle Harkings, MD; Katie McCallum. Robert Annett, PhD (Co-Investigator, 1993-2004); Teresa Archibeque (1994-1999); Naim Bashir, MD (Co-Investigator, 1998-2005); H. Selda Bereket (1995-1998); Marisa Braun (1996-1999); Carrie Bush (1995-1999); Shannon C. Bush (2002-2007); Michael Clayton, MD (Co-Investigator, 1999-2001); Angel Colon-Semidey, MD (Co-Investigator, 1997-2000); Sara Devault (1993-1997); Anna Esparham (2004-2007); Roni Grad, MD (Co-Investigator, 1993-1995); David Hunt, RRT (1995-2004); Jeanne Larsson, RN (1995-1996); Sandra McClelland, RN (Coordinator, 1993-1995); Bennie McWilliams, MD (Co-Investigator, Director, 1992-1998); Elisha Montoya (1997-2000); Margaret Moreshead (1996-1999); Shirley Murphy, MD (Co-Investigator, 1992-1994); Barbara Ortega, RRT (1993-1999); David Weers (1997-1998); Jose Zayas (1995-1996).

Washington University, St Louis, Mo: Robert C. Strunk, MD (Director); Leonard Bacharier, MD (Co-Investigator); Denise Rodgers, RPFT (Coordinator). Ellen Albers, RN, CNS-P, MSN (1997-1999); Gregg Belle, MA (1996-2001); Gordon R. Bloomberg, MD (CoInvestigator, 1994-2007); W. Patrick Buchanan (1998-2001); Mary Caesar, MHS (1993-1996); James M. Corry, MD (Co-Investigator, 1994-2004); Karen DeMuth (2006-2007); Marisa Dolinsky, MA (1996-2001); Edwin B. Fisher, PhD (1993-2001); Stephen J. Gaioni, PhD (1993-2001); Emily Glynn, RN, MSN, CSPNP (1993-2001); Bernadette D. Heckman, MA (1996-2001); Debra Kemp, RN, BSN (1994-2001); Lila Kertz, MSN, RN, CPNP (2005-2007); Claire Lawhon (1994-2003); Valerie Morgan, RRT (2000-2004); Cynthia Moseid (1997); Tina Oliver-Welker, CRTT (1994-2007); Diana Richardson (1994-1997); Elizabeth Ryan, PhD (1994-1997); Sharon Sagal, MD (1996-2001); Thomas F. Smith, MD (1993-1998); Susan Sylvia, PhD (1994-1997); Carl Turner (1995-1997); Deborah K. White, RPFT, RRT (1994-2007).

Resource centers

Data Coordinating Center, Johns Hopkins University, Baltimore, Md: James Tonascia, PhD (Director). Patricia Belt; Karen Collins; Betty Collison; John Dodge; Michele Donithan, MHS; Cathleen Ewing; Rosetta Jackson; Patrick May, MS; Jill Meinert; Girlie Reyes; Michael Smith; Alice L. Sternberg, ScM; Mark L. Van Natta, MHS; Annette Wagoner; Laura Wilson, ScM; Robert Wise, MD;

Katherine Yates, ScM.

Project Office, National Heart, Lung, and Blood Institute, Bethesda, Md: Virginia Taggart, MPH (Project Officer); Lois Eggers; James Kiley, PhD; Howard Moore; Gang Zheng, PhD. Paul Albert, PhD (1991-1999); Suzanne Hurd, PhD (1991-1999); Sydney Parker, PhD (1991-1994); Pamela Randall (1992-2003); Margaret Wu, PhD (1991-2001).

Committees

Data and Safety Monitoring Board: Michelle Cloutier, MD (Chair); John Connett, PhD; Leona Cuttler, MD; Frank Gilliland, MD,

PhD. Clarence E. Davis, PhD (1993-2003); Howard Eigen, MD (1993-2009, Chair); David Evans, PhD (1993-2007); Meyer Kattan, MD (1993-2007); Rogelio Menendez, MD (1993-2007); F. Estelle R. Simons, MD (1993-2007); Sanford Leikin, MD (1993-1999). Steering Committee: Robert Strunk, MD (Study Chair); N. Franklin Adkinson, MD; Robert Annett, PhD (1992-1995, 1997-1999); Bruce Bender, PhD; Mary Caesar, MHS (1994-1996); Reuben Cherniack, MD (Study Chair 1993-2007); Ronina Covar, MD; Thomas R. DuHamel, PhD (1992-1994, 1996-1999); Anne Fuhlbrigge, MD; Hartmut Grasemann, MD; H. William Kelly, PharmD; Henry Levison, MD (1992-1996); Alan Lincoln, PhD (1994-1995); Ian MacLusky, MD (1999-2006); Bennie McWilliams, MD (1992-1998); Curtis L. Meinert, PhD; Sydney Parker, PhD (1991-1994); Hengameh H. Raissy, Pharm D; Joe Reisman, MD, FRCP(C), MBA (1991-1999); Denise Rodgers; Kay Seligsohn, PhD (1996-1997); Gail G. Shapiro, MD (1991-2006); Marian Sharpe (1993-1994); D. Sundström (1998-1999); Stanley Szefler, MD; Virginia Taggart, MPH; Martha Tata, RN (1996-1998); James Tonascia, PhD; Scott Weiss, MD, MS; Barbara Wheeler, RN, BSN (1993-1994); Paul Williams, MD; Robert Wise, MD; Robert Zeiger, MD, PhD.

Disclosure of potential conflict of interest: The rest of the authors declare that they have no relevant conflicts of interest. 
response to inhaled corticosteroids, ${ }^{1,3}$ supporting that BDR has prognostic and therapeutic relevance. The BDR test provides additional information to the clinical history and is recommended by international guidelines as an adjunct to the clinical history in the diagnosis of asthma. ${ }^{4}$

BDR can be expressed by using different methods, with the 3 most common being the percentage of $\mathrm{FEV}_{1}$, the percentage of the initial predicted value for $\mathrm{FEV}_{1}$, and absolute change in $\mathrm{FEV}_{1}$ after administration of a short-acting bronchodilator. A significant BDR is commonly defined as a $12 \%$ or greater and $200 \mathrm{~mL}$ or greater change in $\mathrm{FEV}_{1}$ from baseline. ${ }^{5}$ This $12 \%$ criterion, which was recently reaffirmed in a large international study, ${ }^{6}$ approximates the 95th percentile for percentage change in $\mathrm{FEV}_{1}$ after bronchodilator administration in general population studies, which mainly consist of adults. ${ }^{7}$ The forced oscillation technique, which provides information on airway resistance and reactance, has also been used to measure response to bronchodilators and to differentiate between asthmatic and nonasthmatic patients, ${ }^{8,9}$ especially in younger children who are unable to cooperate during spirometric testing. However, this technique is not widely used because standardized guidelines are lacking.

Although the National Asthma Education and Prevention Program's Expert Panel Report 3 uses the $12 \%$ cutoff as evidence of airway reversibility in establishing the diagnosis of asthma ${ }^{4}$ and this cutoff is used to include subjects in several childhood asthma trials, ${ }^{10,11}$ the validity of the $12 \%$ cutoff has been questioned in the pediatric population. ${ }^{12} \mathrm{BDR}$ tends to increase with decreasing baseline $\mathrm{FEV}_{1} \cdot{ }^{13}$ In subjects with low baseline $\mathrm{FEV}_{1}$, small changes in absolute $\mathrm{FEV}_{1}$ in response to a bronchodilator translate into large percentage changes in $\mathrm{FEV}_{1}$. Because most children with asthma have baseline $\mathrm{FEV}_{1}$ within the normal reference range, the increase in $\mathrm{FEV}_{1}$ after bronchodilator administration is limited. Dundas et al ${ }^{14}$ suggest that a $9 \%$ or greater increase in $\mathrm{FEV}_{1}$ provided the most acceptable sensitivity (50\%) and specificity (86\%) to detect previous wheeze in 5- to 10-year-old children. These results were corroborated by a more recent study showing that a BDR of $9 \%$ or greater was optimal at differentiating asthmatic from nonasthmatic children with similar sensitivity and specificity. ${ }^{12}$ This study was performed in a predominantly Hispanic cohort and thus might have limited generalizability to children of other ethnicities.

In this study we determined the BDR cutoff that best differentiates between children with mild-to-moderate asthma and children without asthma in a large and predominantly white population. We hypothesized that a BDR cutoff of $12 \%$ would be specific but not sufficiently sensitive for diagnosing asthma in children.

\section{METHODS}

\section{Subjects}

Participants from 3 pediatric cohorts were included in this study. Asthma cases consisted of children enrolled in the Childhood Asthma Management Program (CAMP). The demographics of the CAMP subjects and the study design have been previously reported. ${ }^{15}$ Briefly, this multicenter trial randomized 1041 children with mild-to-moderate asthma aged 5 to 13 years to budesonide, nedocromil, or placebo. Children were included if they had asthma symptoms 2 or more times per week, used an asthma medication daily, or used an inhaled bronchodilator twice per week for 6 or more months and had a positive methacholine challenge test result. The long-term effects of these treatments on lung growth were evaluated. ${ }^{15}$ Follow-up visits occurred at 2 and 4 months after randomization and every 4 months thereafter for an average of 4.3 years. 
The control patients for this study were selected from 2 pediatric general population cohorts. Project Viva is a prospective cohort study examining the effect of prenatal and perinatal factors on maternal and child health. Details of the study design have been described previously. ${ }^{16}$ This prebirth cohort consisted of 2128 singleton infants, the mothers of whom were recruited from Harvard Vanguard Medical Associates, a multispecialty group practice in eastern Massachusetts. Of these children, 1116 attended Project Viva's 7-year in-person visit, 819 of whom attempted the BDR test and 468 had valid results. The Home Allergens cohort is a birth cohort of children with a parental history of allergy or asthma. Details of the study design have been published. ${ }^{17}$ Five hundred five infants were recruited within 48 hours of birth in the metropolitan Boston area. Telephone questionnaires about symptoms and diagnoses of atopic disease were administered every 2 months for the first 2 years of life and then every 6 months. A total of 284 children were followed until age 12 years, when 250 of them performed the bronchodilator test. Subjects from these 2 population-based cohorts were selected as control subjects if they had never been given a diagnosis of asthma or had never wheezed, both assessed through a questionnaire or interview ( $n=197$ in Project Viva and $\mathrm{n}=53$ in Home Allergens).

In all 3 cohorts the children's parents or guardians provided informed consent, and the study was approved by the respective local institutional review board.

\section{Spirometry and BDR}

In CAMP the BDR test was performed at randomization and at subsequent visits during which a methacholine challenge was not administered. ${ }^{18}$ Spirometry was performed at least 4 hours after the last use of a short-acting bronchodilator and at least 24 hours after the last use of a long-acting bronchodilator. For the purpose of this analysis, we used the BDR test at randomization, at which point subjects had been off their regular asthma medications for at least 28 days but were allowed to use a rescue bronchodilator and prednisone, if needed. The BDR test was performed around age 7 years for Project Viva (range, 6.6-10.9 years) and at age 12 years for Home Allergens (range, 11.1-12.7 years). In Project Viva spirometry was performed with the EasyOne Spirometer (NDD Medical Technologies, Andover, Mass). In Home Allergens spirometry was performed by using the Eagle+ spirometer (Collins Medical, Louisville, Colo). In all 3 cohorts postbronchodilator spirometric measures were obtained at least 15 minutes after administration of 2 puffs ( $90 \mu \mathrm{g}$ per puff) of albuterol. Spirometric performance was required to meet American Thoracic Society criteria for acceptability and reproducibility, with each subject producing at least 3 acceptable spirograms, 2 of which must have been reproducible. ${ }^{19}$

In this study we defined BDR as a percentage change in absolute $\mathrm{FEV}_{1}$ after albuterol administration, as follows:

$$
\text { (Postbronchodilator } \begin{aligned}
\mathrm{FEV}_{1}- & \text { Prebronchodilator } \mathrm{FEV}_{1} \text { )/Prebronchodilator } \\
& \mathrm{FEV}_{1} \times 100 .
\end{aligned}
$$

Given the lack of consensus in the definition of BDR, we have also calculated BDR as a percentage of the initial predicted value for $\mathrm{FEV}_{1}$ in CAMP, as follows:

$$
\text { (Postbronchodilator } \begin{aligned}
\mathrm{FEV}_{1}- & \text { Prebronchodilator } \mathrm{FEV}_{1} \text { ) } / \text { Prebronchodilator } \\
& \text { percent predicated } \mathrm{FEV}_{1} \times 100
\end{aligned}
$$

and compared it with the former definition. 


\section{Statistical analysis}

A descriptive analysis of baseline characteristics was performed. A Pearson correlation test was used to evaluate the association between the 2 definitions of BDR in CAMP. The study population was divided into a training set, consisting of a random selection of 50 cases and 50 control subjects, and a validation set, consisting of the remaining subjects, to evaluate the diagnostic accuracy of the BDR test. This allows for validation of results within our cohorts. Receiver operating characteristic curves were constructed, and areas under the curve (AUCs) were calculated for different BDR thresholds (R package pROC) ${ }^{20}$ The AUCs for different thresholds were compared by using the DeLong test. A sensitivity analysis was performed to assess how the diagnostic accuracy of the BDR test varies across different severities of asthma. AUCs were examined for the CAMP subjects with and without evidence of baseline airflow obstruction $\left(\mathrm{FEV}_{1}\right.$ percent predicted $<80 \%$ and $\ 80 \%$, respectively). $P$ values are 2 -sided. All analyses were performed with R software, version 2.12.1 (www.r-project.org).

\section{RESULTS}

\section{Patient demographics}

A total of 1041 children with mild-to-moderate asthma were included from the CAMP cohort (cases). Control subjects consisted of 250 children from the Project Viva and Home Allergens cohorts who had no history of wheezing and asthma at the time of the BDR test. Baseline characteristics of the study population by asthma status are presented in Table I. Although their baseline $\mathrm{FEV}_{1}$ percent predicted values were similar and within normal limits $(93.7 \% \pm 14.3 \%$ in cases and $98.4 \% \pm 12.2 \%$ in control subjects), the mean BDR differed between the 2 groups, as expected. Both groups consisted of predominantly white subjects. The control subjects from Project Viva were younger than those from Home Allergens ( $7.9 \pm 0.8$ vs $11.7 \pm 0.5$ years, respectively), but other baseline characteristics were similar, including race/ethnicity, baseline $\mathrm{FEV}_{1}$ percent predicted, and BDR (see Table E1 in this article's Online Repository at www.jacionline.org). Baseline characteristics of subjects who performed a BDR test and those who did not are shown in Table E2 in this article's Online Repository at www.jacionline.org. In both Project Viva and Home Allergens subjects who underwent the BDR test had a higher prevalence of asthma and wheezing, whereas other measures of atopy were similar to those of the subjects who did not perform the test. However, the control subjects selected for this analysis were not different from the control subjects who did not undergo the BDR test in terms of age, anthropometric measures, and race (see Table E3 in this article's Online Repository at www.jacionline.org).

\section{Comparison of different definitions of BDR}

Given the lack of consensus on how to define BDR, we compared BDR defined as (1) percentage of initial $\mathrm{FEV}_{1}$ and (2) percentage of initial predicted value for $\mathrm{FEV}_{1}$. In CAMP asthmatic patients these 2 definitions were almost perfectly correlated (Pearson correlation, $r$ $=0.958 ;$ Fig 1$)$. Therefore we used BDR as a percentage of initial $\mathrm{FEV}_{1}$ in the subsequent analyses because the commonly accepted $12 \%$ cutoff is based on this definition.

\section{Diagnostic accuracy of the BDR test}

For the purposes of this analysis, the study population was divided into a training set and a validation set. In the training set $(\mathrm{n}=100)$ the BDR test differentiated children with and without asthma with a moderate accuracy (AUC, $74.5 \%$; 95\% CI, $69.0 \%$ to $80.0 \%$ ). The AUC was replicated in the validation set at $73.3 \%$ (95\% CI, 69.2\% to 77.2\%; Fig 2). Similar AUCs were obtained when the analysis was stratified by sex (AUC, $72.5 \%$ in male and $74.0 \%$ in female subjects). Table II shows the sensitivity and specificity for different BDR 
cutoff values. Despite good specificity (89.5\%), a cutoff of $12 \%$ offered low sensitivity (35.6\%). A BDR cutoff of $8 \%$ (sensitivity, 54.4\%; specificity, 76.5\%) or less performed significantly better than a cutoff of $12 \%$ (comparing AUCs: $P=.031,8 \%$ vs $12 \%$ ). A cutoff of 5\% offered the highest AUC (68.6\%), with a sensitivity of $73.6 \%$ and specificity of $63.5 \%$ (Table II).

\section{Sensitivity analysis}

A total of 148 CAMP subjects had an initial $\mathrm{FEV}_{1}$ percent predicted value of less than $80 \%$. Their mean BDR was $23.6 \% \pm 14.6 \%$. The BDR test differentiated these subjects from control subjects with a high accuracy (AUC, $93.1 \%$; 95\% CI, 90.4\% to 95.7\%; Fig 3, $A$ ). In contrast, the diagnostic accuracy of the BDR test was lower for CAMP subjects with an initial $\mathrm{FEV}_{1}$ percent predicted value of $80 \%$ or greater $(\mathrm{n}=881$; AUC, $71.0 \% ; 95 \% \mathrm{CI}$, $67.2 \%$ to $74.8 \%$; Fig $3, B$ ). This subset of children also had a lower BDR (mean, 8.6 \pm 7.4 ).

\section{DISCUSSION}

In this analysis of the diagnostic accuracy of the BDR test, we found that the commonly used BDR cutoff of $12 \%$ was associated with a poor sensitivity and that a BDR cutoff of $8 \%$ or lower performed better than $12 \%$ at differentiating between children with and without asthma using 3 predominantly white populations.

The BDR test is recommended as an adjunct in the diagnosis of asthma, along with the clinical history and signs of inflammation, such as eosinophilia and increased IgE levels. This test assesses the degree of reversible airway obstruction with the administration of a bronchodilator and has been shown to provide independent information in the assessment of asthma. ${ }^{21}$ The widely accepted BDR cutoff of $12 \%$ is based on general population and asthmatic patient studies consisting of mostly adults, who might have a higher interindividual variability in baseline $\mathrm{FEV}_{1}$. A recent international study examined the BDR test in more than 3900 healthy adult never smokers participating in the population-based Burden of Obstructive Lung Disease study. ${ }^{6}$ The authors reaffirmed that the 95th percentile for BDR was $12 \%$, with BDR expressed as a percentage of absolute baseline $\mathrm{FEV}_{1}$. Although this study provides confirmation to current guidelines in adults, our findings suggest that this cutoff might not be appropriate for the diagnosis of asthma in children given its poor sensitivity, which could result in missed cases of asthma. Studies have shown that the BDR tends to increase with decreasing baseline lung function, ${ }^{13}$ and therefore BDR might be higher in asthmatic adults. In the Burden of Obstructive Lung Disease study cohort, the mean percent predicted $\mathrm{FEV}_{1}$ values in the entire cohort were generally lower than in our study. In contrast, in asthmatic children baseline lung function tends to remain normal, ${ }^{22,23}$ even in a subset of patients with severe asthma ${ }^{24}$; hence a $12 \%$ change from baseline with bronchodilator might be difficult to reach. This inference is in accordance with our sensitivity analysis, in which only a minority of CAMP subjects had a baseline $\mathrm{FEV}_{1}$ of less than $80 \%$ of predicted value.

The choice of an optimal BDR cutoff is complex. Maximizing sensitivity and specificity is key in the evaluation of any diagnostic test. In the case of asthma, there is no clear consensus on what is an acceptable tradeoff between these 2 test properties because this decision depends on the treatment threshold. The treatment threshold is in turn determined by the costs and benefits of the treatment and consideration of the harm caused by the treatment of false-positive cases and the nontreatment of false-negative cases. Furthermore, the positive and negative predictive values will depend on the prevalence of asthma, and these differ from a general pediatrician's office to a pulmonologist's office, where the BDR test is commonly performed. In patients with mild-to-moderate asthma, as with this study population, treatment can consist of a bronchodilator on an as-needed basis or a daily 
inhaled corticosteroid, both with different pharmacologic profiles. Hence choosing an optimal cutoff based on prespecified acceptable values of sensitivity and specificity is difficult. Rather, we have used the area under the receiver operating characteristic curve to guide our selection of an appropriate cutoff.

Although a BDR cutoff of $12 \%$ provided good specificity (89.5\%), it offered poor sensitivity $(35.6 \%)$. A cutoff of $8 \%$, which had a significantly better AUC than $12 \%$, was associated with a sensitivity of $54.4 \%$ and a specificity of $76.5 \%$. The higher performance of a BDR cutoff of less than $12 \%$ is in accordance with a previous study of the BDR test in a mainly Hispanic pediatric population, which identified a BDR cutoff of $9 \%$ as the optimal value, with a sensitivity of $42.5 \%$ and a specificity of $86.3 \% .{ }^{12}$ This suggests that the BDR test is robust enough to withstand variations in ethnicity.

Although our findings identified that a BDR cutoff of $8 \%$ performed significantly better than a cutoff of $12 \%$, it is important to note that changes in $\mathrm{FEV}_{1}$ of less than $8 \%$ are generally considered to be within measurement variability. ${ }^{5,25}$ This variability is likely higher in children given their imperfect technique. Thus using a cutoff of $8 \%$ as a criterion for the diagnosis of asthma might not be appropriate either. For these reasons, we suggest using caution when picking a BDR cutoff to aid in the diagnosis of asthma. Overall, the BDR test performs poorly in diagnosing asthma in children and might be a better reflection of changes in bronchomotor tone in response to bronchodilators, which in turn might reflect the frequency of asthma symptoms or exacerbations.

Based solely on the AUC, our data suggest a BDR cutoff of $5 \%$ as the optimal cutoff (Table II) with a sensitivity of $73.6 \%$ and specificity of $63.5 \%$. This threshold would not be clinically useful given that it is within the range of measurement variability. Interestingly, our sensitivity analysis showed that the diagnostic accuracy of the BDR test was higher for subjects with lower baseline lung function. The optimal BDR cutoff for children with an $\mathrm{FEV}_{1}$ of $80 \%$ of predicted value or less based on the AUC was $11 \%$, reflecting the high mean BDR in these persons compared with control subjects. In contrast, the "optimal" 5\% cutoff derived from the overall data likely reflects that the majority of the cases have mild asthma, with a significant overlap of the BDR between cases and control subjects (Table I).

Although not the focus of this study, it is interesting to consider the consistency with which children with asthma meet the criterion for a BDR cutoff of less than $12 \%$ over time. Using the CAMP cohort, Sharma et $\mathrm{al}^{26}$ reported that, similarly to a cutoff of $12 \%$, a consistent BDR of $10 \%$ or greater over 4 years predicted nighttime awakenings, oral steroid bursts, and emergency department visits or hospitalizations. Future studies should explore whether a consistent BDR response at lower thresholds would also predict future clinical outcomes and diagnoses of asthma.

There is no clear consensus on how the BDR should be expressed. Some authors suggest an advantage of using BDR as a percentage of the initial predicted value for $\mathrm{FEV}_{1}$ over a percentage of initial $\mathrm{FEV}_{1}$ because this definition is less dependent on baseline lung function. ${ }^{25,27}$ In our population of children with mild-to-moderate asthma, these 2 definitions of BDR were highly correlated $(r=0.958)$. This agreement is in accordance with the fact that most of these children had normal baseline $\mathrm{FEV}_{1}$ percent predicted values. On the basis of these results, the use of either definition of BDR might be acceptable in children with mild-to-moderate asthma, whereas BDR as a percentage of predicted $\mathrm{FEV}_{1}$ should be considered in populations with a high heterogeneity in baseline lung function, such as children with severe asthma. ${ }^{24}$

Our findings can have varied and wide-ranging implications, depending on the clinical situation. Clinically, the BDR test is an imperfect diagnostic test, as suggested by the AUC 
of less than $70 \%$ for any cutoff, and it should be used only as an adjunct for the diagnosis of asthma. Using a cutoff of $12 \%$ or greater as "significant" bronchodilation might also result in underdiagnosis and undertreatment of asthma, given the poor associated sensitivity. In asthma research several studies use the $12 \%$ BDR cutoff to select patients for inclusion in the study. In children this criterion will lead to a subset of patients selected for a higher degree of airway airflow obstruction, which might limit the generalizability of the results. In addition, it might be more difficult to recruit the number of patients required given the restriction by this criterion. This consideration is especially important in asthma genetic and pharmacogenetic studies, in which large sample sizes are often required. On the other hand, in intervention studies a higher cutoff could select for children who have a higher chance of showing an intervention effect.

Several limitations of our study need to be addressed. This study was designed to examine how well the BDR test differentiates children with mild-to-moderate asthma from children without asthma. This is also a predominantly white population. The diagnostic accuracy of the BDR test was derived from these populations and might not be generalizable to other situations, such as more severe asthma. However, previous studies found similar results, ${ }^{12}$ including one comparing subjects with mild intermittent wheeze with control subjects. ${ }^{14}$ This supports the use of the BDR test as an adjunct in patients with different degrees of symptom severity. Asthma is a heterogeneous disease, and in addition to pharmacogenetic predisposition in the response to bronchodilators, ${ }^{28-30}$ there is evidence that patients with the allergic asthma phenotype have higher BDR, ${ }^{31}$ whereas others have a lower response. ${ }^{32}$ Thus the diagnostic value of the BDR test might depend on the asthma phenotype. Finally, a minority of subjects in CAMP received rescue prednisone in the weeks before randomization. Although these are short courses of corticosteroids, this could have affected the participants' responsiveness to a bronchodilator and made cases more similar to control subjects, which would lead to a bias toward a decreased accuracy of the BDR test in this study.

In conclusion, this study demonstrated that the commonly used BDR cutoff of $12 \%$ in adults offers poor sensitivity as an adjunct test in the diagnosis of asthma in children. Our results from populations of children with mild-to-moderate asthma suggest that a BDR cutoff of $8 \%$ or less performed significantly better than a cutoff of $12 \%$. However, given the variability of this test in children, it might not be appropriate to choose $8 \%$ as the optimal cutoff. Thus we advise against choosing a specific BDR cutoff for the diagnosis of asthma but rather to use the BDR test as a guide in the treatment and diagnosis of asthma because the persistence of a positive response might be associated with worse clinical outcomes in asthmatic patients over time.

\section{Supplementary Material}

Refer to Web version on PubMed Central for supplementary material.

\section{Acknowledgments}

CAMP CREDIT ROSTER

Source of funding The CAMP trial and CAMP Continuation Study were supported by contracts NO1-HR-16044, 16045, 16046, 16047, 16048, 16049, 16050, 16051, and 16052 with the National Heart, Lung, and Blood Institute (NHLBI) and General Clinical Research Center grants M01RR00051, M01RR0099718-24, M01RR02719-14, and RR00036 from the National Center for Research Resources. The CAMP Continuation Study Phases 2 and 3 were supported by grants U01HL075232, U01HL075407, U01HL075408, U01HL075409, U01HL075415, U01HL075416, U01HL075417, U01HL075419, U01HL075420, and U01HL075408 from the NHLBI. The National Jewish Health site was also supported in part by Colorado CTSA grant UL1RR025780 from the National 
Center for Research Resources/National Institutes of Health (NIH) and UL1TR000154 from the National Center for Advancing Transitional Sciences/NIH.

The Childhood Asthma Management Program is supported by contracts NO1-HR-16044, 16045, 16046, 16047, $16048,16049,16050,16051$, and 16052 with the National Heart, Lung, and Blood Institute and General Clinical Research Center grants M01RR00051, M01RR0099718-24, M01RR02719-14, and RR00036 from the National Center for Research Resources. Additional support for this research came from grants P50 HL67664, U01 HL65899, and T32 HL07427 from the National Institutes of Health and the National Heart, Lung, and Blood Institute. Home Allergens is funded by National Institute of Allergy and Infectious Diseases/R01 grant AI035786. Project Viva is funded by R01 HL064925 and R01 HD034568.

S. M. Tse, M. W. Gillman, and K. G. Tantisira have been supported by/have received one or more grants from or have one or more grants pending with the National Institutes of Health (NIH). D. R. Gold has been supported by one or more grants from the National Institute of Allergy and Infectious Diseases. A. L. Fuhlbrigge has been supported by one or more grants from and has received support for travel from the National Heart, Lung, and Blood Institute (NHLBI); is a Board member for Merck; has consultancy arrangements with Merck, GlaxoSmithKline, ICON Medical Imaging, Sunovion, the Lovelace Respiratory Research Institute, and Dmagi; and has received one or more grants from or has one or more grants pending with the NHLBI and the Agency for Healthcare Research and Quality. A. A. Litonjua has been supported by one or more grants from the NIH and has received royalties from UpToDate.

\section{Abbreviations used}

$\begin{array}{ll}\text { AUC } & \text { Area under the curve } \\ \text { BDR } & \text { Bronchodilator response } \\ \text { CAMP } & \text { Childhood Asthma Management Program }\end{array}$

\section{REFERENCES}

1. Tantisira KG, Fuhlbrigge AL, Tonascia J, Van Natta M, Zeiger RS, Strunk RC, et al. Bronchodilation and bronchoconstriction: predictors of future lung function in childhood asthma. J Allergy Clin Immunol. 2006; 117:1264-71. [PubMed: 16750985]

2. Puckett JL, Taylor RW, Leu SY, Guijon OL, Aledia AS, Galant SP, et al. An elevated bronchodilator response predicts large airway inflammation in mild asthma. Pediatr Pulmonol. 2010; 45:174-81. [PubMed: 20082343]

3. Kerstjens HA, Brand PL, Quanjer PH, van der Bruggen-Bogaarts BA, Koeter GH, Postma DS. Variability of bronchodilator response and effects of inhaled corticosteroid treatment in obstructive airways disease. Dutch CNSLD Study Group. Thorax. 1993; 48:722-9. [PubMed: 8153921]

4. Expert Panel Report 3 (EPR-3): guidelines for the diagnosis and management of asthma-summary report 2007. J Allergy Clin Immunol. 2007; 120(suppl):S94-138. [PubMed: 17983880]

5. Pellegrino R, Viegi G, Brusasco V, Crapo RO, Burgos F, Casaburi R, et al. Interpretative strategies for lung function tests. Eur Respir J. 2005; 26:948-68. [PubMed: 16264058]

6. Tan WC, Vollmer WM, Lamprecht B, Mannino DM, Jithoo A, Nizankowska-Mogilnicka E, et al. Worldwide patterns of bronchodilator responsiveness: results from the Burden of Obstructive Lung Disease study. Thorax. 2012; 67:718-26. [PubMed: 22544896]

7. Lorber DB, Kaltenborn W, Burrows B. Responses to isoproterenol in a general population sample. Am Rev Respir Dis. 1978; 118:855-61. [PubMed: 736356]

8. Vu LT, Demoulin B, Nguyen MT, Nguyen YT, Marchal F. Respiratory impedance and response to salbutamol in asthmatic Vietnamese children. Pediatr Pulmonol. 2010; 45:380-6. [PubMed: 20306537]

9. Shin YH, Jang SJ, Yoon JW, Jee HM, Choi SH, Yum HY, et al. Oscillometric and spirometric bronchodilator response in preschool children with and without asthma. Can Respir J. 2012; 19:273-7. [PubMed: 22891189]

10. Szefler SJ, Phillips BR, Martinez FD, Chinchilli VM, Lemanske RF, Strunk RC, et al. Characterization of within-subject responses to fluticasone and montelukast in childhood asthma. J Allergy Clin Immunol. 2005; 115:233-42. [PubMed: 15696076] 
11. Lemanske RF Jr, Mauger DT, Sorkness CA, Jackson DJ, Boehmer SJ, Martinez FD, et al. Step-up therapy for children with uncontrolled asthma receiving inhaled corticosteroids. N Engl J Med. 2010; 362:975-85. [PubMed: 20197425]

12. Galant SP, Morphew T, Amaro S, Liao O. Value of the bronchodilator response in assessing controller naive asthmatic children. J Pediatr. 2007; 151:457-62. e1. [PubMed: 17961685]

13. Weir DC, Sherwood Burge P. Measures of reversibility in response to bronchodilators in chronic airflow obstruction: relation to airway calibre. Thorax. 1991; 46:43-5. [PubMed: 1831301]

14. Dundas I, Chan EY, Bridge PD, McKenzie SA. Diagnostic accuracy of bronchodilator responsiveness in wheezy children. Thorax. 2005; 60:13-6. [PubMed: 15618576]

15. Long-term effects of budesonide or nedocromil in children with asthma. The Childhood Asthma Management Program Research Group. N Engl J Med. 2000; 343:1054-63. [PubMed: 11027739]

16. Gillman MW, Rich-Edwards JW, Rifas-Shiman SL, Lieberman ES, Kleinman KP, Lipshultz SE. Maternal age and other predictors of newborn blood pressure. J Pediatr. 2004; 144:240-5. [PubMed: 14760269]

17. Gold DR, Burge HA, Carey V, Milton DK, Platts-Mills T, Weiss ST. Predictors of repeated wheeze in the first year of life: the relative roles of cockroach, birth weight, acute lower respiratory illness, and maternal smoking. Am J Respir Crit Care Med. 1999; 160:227-36. [PubMed: 10390405]

18. The Childhood Asthma Management Program (CAMP): design, rationale, and methods. Childhood Asthma Management Program Research Group. Control Clin Trials. 1999; 20:91-120.

19. Miller MR, Hankinson J, Brusasco V, Burgos F, Casaburi R, Coates A, et al. Standardisation of spirometry. Eur Respir J. 2005; 26:319-38. [PubMed: 16055882]

20. Robin X, Turck N, Hainard A, Tiberti N, Lisacek F, Sanchez JC, et al. pROC: an open-source package for $\mathrm{R}$ and $\mathrm{S}+$ to analyze and compare ROC curves. BMC Bioinformatics. 2011; 12:77. [PubMed: 21414208]

21. Holt EW, Cook EF, Covar RA, Spahn J, Fuhlbrigge AL. Identifying the components of asthma health status in children with mild to moderate asthma. J Allergy Clin Immunol. 2008; 121:117580. [PubMed: 18466785]

22. Bacharier LB, Strunk RC, Mauger D, White D, Lemanske RF Jr, Sorkness CA. Classifying asthma severity in children: mismatch between symptoms, medication use, and lung function. Am J Respir Crit Care Med. 2004; 170:426-32. [PubMed: 15172893]

23. Paull K, Covar R, Jain N, Gelfand EW, Spahn JD. Do NHLBI lung function criteria apply to children? A cross-sectional evaluation of childhood asthma at National Jewish Medical and Research Center, 1999-2002. Pediatr Pulmonol. 2005; 39:311-7. [PubMed: 15678505]

24. Fitzpatrick AM, Teague WG, Meyers DA, Peters SP, Li X, Li H, et al. Heterogeneity of severe asthma in childhood: confirmation by cluster analysis of children in the National Institutes of Health/National Heart, Lung, and Blood Institute Severe Asthma Research Program. J Allergy Clin Immunol. 2011; 127:382-9. e1-13. [PubMed: 21195471]

25. Brand PL, Quanjer PH, Postma DS, Kerstjens HA, Koeter GH, Dekhuijzen PN, et al. Interpretation of bronchodilator response in patients with obstructive airways disease. The Dutch Chronic NonSpecific Lung Disease (CNSLD) Study Group. Thorax. 1992; 47:429-36. [PubMed: 1496502]

26. Sharma S, Litonjua AA, Tantisira KG, Fuhlbrigge AL, Szefler SJ, Strunk RC, et al. Clinical predictors and outcomes of consistent bronchodilator response in the childhood asthma management program. J Allergy Clin Immunol. 2008; 122:921-8. e4. [PubMed: 18848350]

27. Waalkens HJ, Merkus PJ, van Essen-Zandvliet EE, Brand PL, Gerritsen J, Duiverman EJ, et al. Assessment of bronchodilator response in children with asthma. Dutch CNSLD Study Group. Eur Respir J. 1993; 6:645-51.

28. Duan QL, Gaume BR, Hawkins GA, Himes BE, Bleecker ER, Klanderman B, et al. Regulatory haplotypes in ARG1 are associated with altered bronchodilator response. Am J Respir Crit Care Med. 2011; 183:449-54. [PubMed: 20851928]

29. Duan QL, Du R, Lasky-Su J, Klanderman BJ, Partch AB, Peters SP, et al. A polymorphism in the thyroid hormone receptor gene is associated with bronchodilator response in asthmatics.

Pharmacogenomics J. 2013; 13:130-6. [PubMed: 22212731] 
30. Choudhry S, Que LG, Yang Z, Liu L, Eng C, Kim SO, et al. GSNO reductase and beta2-adrenergic receptor gene-gene interaction: bronchodilator responsiveness to albuterol. Pharmacogenet Genomics. 2010; 20:351-8. [PubMed: 20335826]

31. Dweik RA, Sorkness RL, Wenzel S, Hammel J, Curran-Everett D, Comhair SA, et al. Use of exhaled nitric oxide measurement to identify a reactive, at-risk phenotype among patients with asthma. Am J Respir Crit Care Med. 2010; 181:1033-41. [PubMed: 20133930]

32. Benton AS, Wang Z, Lerner J, Foerster M, Teach SJ, Freishtat RJ. Overcoming heterogeneity in pediatric asthma: tobacco smoke and asthma characteristics within phenotypic clusters in an African American cohort. J Asthma. 2010; 47:728-34. [PubMed: 20684733] 


\section{Clinical implications}

The BDR reflects the reversibility of airflow obstruction. The commonly used cutoff of $12 \%$ is associated with poor sensitivity in the diagnosis of asthma in children and might result in missed cases of asthma. 
Relation between BDR expressed as percent of baseline FEV1 and as percent of baseline predicted value for FEV1

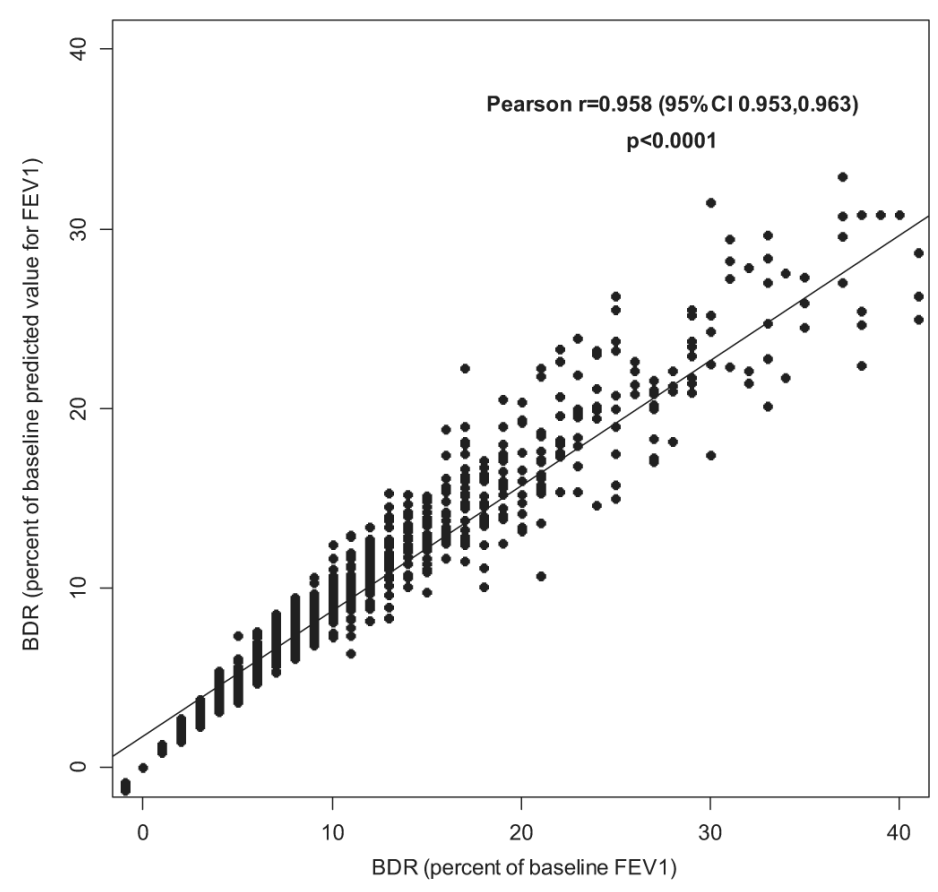

FIG 1.

Correlation between BDR expressed as percentage of baseline $\mathrm{FEV}_{1}$ and as percentage of baseline predicted value for $\mathrm{FEV}_{1}$ in $\mathrm{CAMP}(\mathrm{n}=1041)$. 


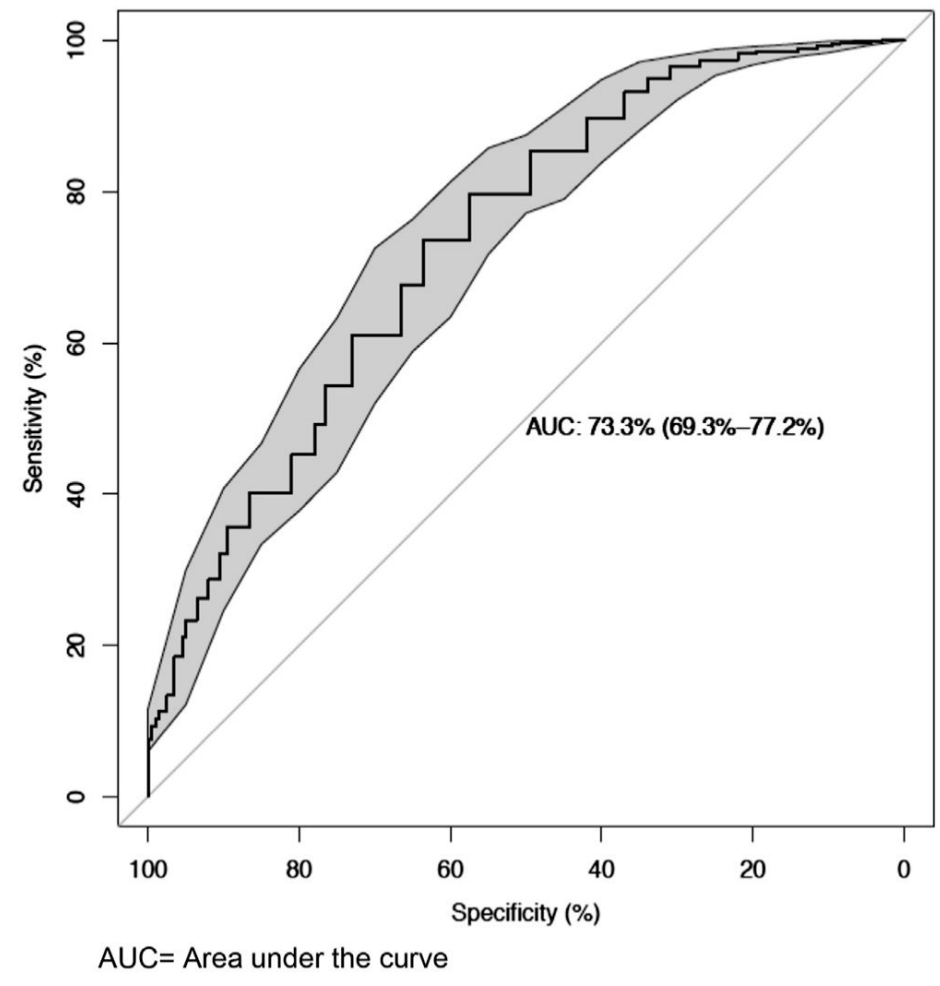

FIG 2.

Receiver operating characteristic curve in validation set comparing 991 patients with mildto-moderate asthma from CAMP and 200 control subjects from Project Viva and Home Allergens. 

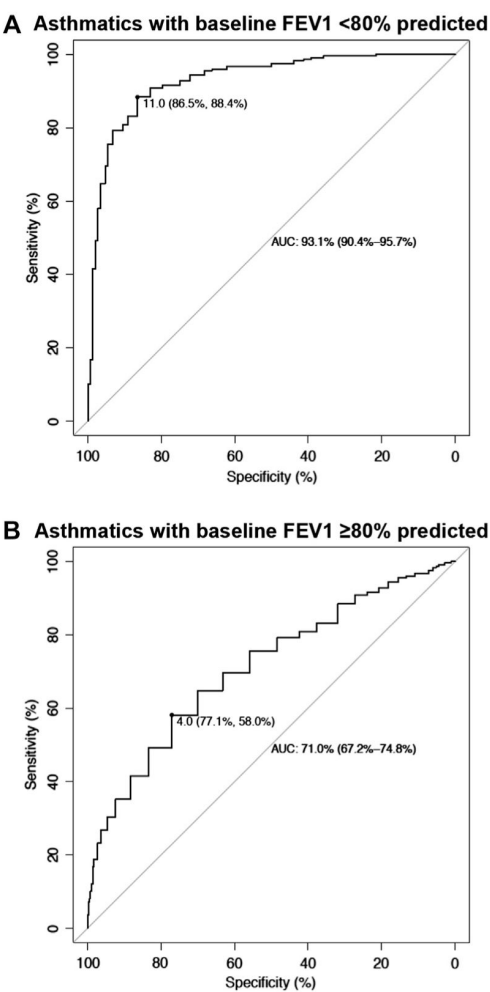

FIG 3.

Separate receiver operating characteristic curves comparing 148 asthmatic patients with a baseline $\mathrm{FEV}_{1}$ of less than $80 \%$ of predicted value and 250 control subjects (A) and 881 asthmatic patients with a baseline $\mathrm{FEV}_{1}$ of $80 \%$ or greater and 250 control subjects (B). The best threshold based on the AUC, along with its specificity and sensitivity, are shown. 


\section{TABLE I}

Baseline characteristics

\begin{tabular}{lcc}
\hline & Cases (n = 1041) & $\begin{array}{c}\text { Control subjects } \\
(\mathbf{n}=\mathbf{2 5 0})\end{array}$ \\
\hline Male sex, no. (\%) & $621(59.7)$ & $117(46.8)$ \\
Age (y), mean (SD) & $8.9(2.1)$ & $8.7(1.7)$ \\
Height (cm), mean (SD) & $133.6(13.8)$ & $133.0(11.5)$ \\
Weight (kg), mean (SD) & $33.4(12.1)$ & $31.0(8.9)$ \\
BMI (\%), median (IQR) & $68.0(41.3-89.2)$ & $62.4(32.1-82.8)$ \\
Race, no. (\%) & & \\
$\quad$ White & $711(68.3)$ & $190(76.0)$ \\
$\quad$ Black & $138(13.3)$ & $20(8.0)$ \\
Hispanic & $98(9.4)$ & $7(2.8)$ \\
Other & $94(9.0)$ & $33(13.2)$ \\
FEV 1 (L), mean (SD) & $1.65(0.48)$ & $1.72(0.49)$ \\
FEV $1 \%$ predicted), mean (SD) & $93.7(14.3)$ & $98.4(12.2)$ \\
BDR (\%), mean (SD) & $10.7(10.2)$ & $2.7(8.4)$ \\
\hline
\end{tabular}

$B M I$, Body mass index. 


\section{TABLE II}

A BDR cutoff of $8 \%$ or less performed significantly better than a cutoff of $12 \%$

\begin{tabular}{|c|c|c|c|c|}
\hline & Sensitivity & Specificity & $\operatorname{AUC}(95 \% \mathrm{CI})$ & $\begin{array}{c}P \text { value } \\
\text { (comparing } \\
\text { with AUC } \\
\text { for } 12 \% \text { ) }\end{array}$ \\
\hline \multicolumn{5}{|c|}{ BDR cutoff $(\%)$} \\
\hline 12 & 35.6 & 89.5 & $62.5(59.9-65.1)$ & - \\
\hline 11 & 40.1 & 86.5 & $63.3(60.5-66.1)$ & .261 \\
\hline 10 & 45.2 & 81.0 & $63.1(60.0-66.2)$ & .613 \\
\hline 9 & 49.1 & 78.0 & $63.6(60.3-66.8)$ & .414 \\
\hline 8 & 54.4 & 76.5 & $65.4(62.1-68.8)$ & .031 \\
\hline 7 & 61.1 & 73.0 & $67.0(63.6-70.5)$ & .003 \\
\hline 6 & 67.6 & 66.5 & $67.1(63.5-70.7)$ & .007 \\
\hline 5 & 73.6 & 63.5 & $68.6(64.9-72.2)$ & .001 \\
\hline
\end{tabular}

